\title{
KESALAHAN BACAAN AL-QURAN DALAM TILAWAH AL-QURAN DAN KRITERIA EVALUASI
}

\author{
Najmiah Binti Omar \\ Nor Hafizi bin Yusof \\ Fatimah Zaharah Ismail \\ Wan Fajrulhisyam bin Wan Abdullah \\ Universiti Sultan Zainal Abidin, Malaysia
}

\begin{abstract}
Abstrak: Secara umumnya, kesalahan dalam tilawah al-Quran terbagi kepada dua bahagian yaitu kesalahan Jaliyy atau nyata dan kesalahan Khafiyy atau tersembunyi. Kedua-dua kesalahan ini bisa merusak bacaan, mengurangkan kesempurnaan bacaan, tiada ketartilan dalam bacaan al-Quran dan membawa kepada pengurangan markah dalam majelis tilawah alQuran. Kesalahan dalam bacaan al-Quran melibatkan aspek fasahah, suara, tarannum, dan tajwid. Oleh itu, bacaan al-Quran yang sempurna adalah bacaan yang kurang kesalahan daripada ciri-ciri yang disebutkan tadi. Dengan mengenal pasti kesalahan tersebut dapat dijadikan garis panduan secara khusus bagi qari dan qariah yang hendak membaca al-Quran.
\end{abstract}

Kata Kunci: bacaan, Al-Quran, tilawah 


\section{PENDAHULUAN}

Pengertian Kesalahan Jaliyy dan Kesalahan Khafiyy

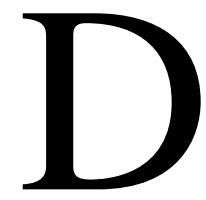
alam ilmu tajwid, kesalahan dalam membaca al Quran ada dua jenis yaitu yang disebut dengan 'Lahn Jaliyy' dan 'Lahn Khafiyy'. Lahn Jaliyy adalah kesalahan yang besar manakala kesalahan Khafiyy adalah kesalahan yang ringan. Kesalahan Jaliyy adalah kesalahan yang jika dilakukan oleh pembaca al-Quran bahkan kesengajaannya menjerumuskannya pada amaliah yang haram seperti tertukarnya huruf-huruf yang dibaca, baris atau harakat yang berubah karena kurangnya sikap ketelitian pembaca. Sedangkan Lahn Khafiyy adalah kesalahan yang tergolong ringan seperti tidak menyempurnakan kaidah panjang sebagaimana yang diminta atau tidak menahan dengungan 'ghunnah' sebagaimana kaidahnya. Kesalahan ini walaupun tergolong ringan, tetapi telah mencemari keindahan al Quran dari segi bacaannya jika tidak diindahkan oleh para pembacanya. Dengan mempelajari tahsin al Quran, maka setiap pembaca telah membangun kepedulian untuk mengenali jenisjenis kesalahan ini dan menghindarinya, maka selamatlah ia dari kesalahan tersebut.

Sebuah artikel kertas kerja daripada Muhammad Syafiee Salihin dan rekan-rekan yang berjudul "Kesalahan Jali Dalam Kalangan Peserta Majelis Tilawah al-
Quran Peringkat Kebangsaan Ke-59 Tahun 2016", menjelaskan tentang dua jenis kesalahan yang terdapat dalam bacaan alQuran yaitu Kesalahan Jaliy dan Kesalahan Khafiy. Kesalahan dalam bacaan al-Quran atau dalam bahasa Arab disebut al-Lahn adalah kesalahan yang berlaku pada i'rab dan berlawanan dengan wajah yang betul pada nahu, manakala dalam ilmu tajwid, alLahn merupakan kesalahan pada bacaan dan terpesong dari yang betul.

Artikel ini juga memuatkan contohcontoh kesalahan jaliy dan khafiy. Bagi kesalahan jaliy, samada menyebabkan perubahan makna atau tidak, ia dikira sebagai kesalahan yang berat dan boleh membawa kepada dosa ke atas pembaca alQuran sekiranya dia mampu untuk belajar. Kesalahan Khafiy pula adalah kesalahan yang dilakukan oleh pembaca al-Quran pada hukum-hukum tajwid seperti menghilangkan sebuah ghunnah atau mad atau idgham.

Kesalahan ini mempunyai pelbagai peringkat antaranya peringkat yang ringan dan peringkat yang lebih ringan umpama kesalahan sebahagian kecil dari tajwid seperti mengurangkan derajat ghunnah yaitu dengung atau meringankan dari hadnya. Hukum kesalahan ini adalah makruh, ada juga pendapat yang lemah mengatakan hukumnya haram karena menjelaskan bacaan yang sahih. Kesalahan Khafiy ini dibagi kepada dua peringkat yaitu pertama: 
Sekiranya kesalahan tersebut menghilangkan hukum yang zahir maka hukumnya adalah haram. Kedua: Sekiranya kesalahan tersebut hanya menghilangkan hukum yang kecil maka hukumnya adalah makruh berbeda dengan kesalahan Jaliy karena hukumnya adalah haram secara qat' $i$.

\section{Kesalahan dalam Tahsin al-Quran Di Kalangan Qari}

Kesalahan dalam tilawah al-Quran boleh merusakkan bacaan dan mencacatkannya. Selain itu, terdapat qari atau qariah melakukan kesalahan yang berulang ketika membaca al-Quran berdasarkan rekod peserta yang menyertai majelis tilawah alQuran (MAIDAM,2014). Oleh itu, kesalahan yang berlaku boleh mengurangkan pemarkahan dalam majelis tilawah al-Quran (MTQ). Pengerusi Jemaah Hakim, Dato' Haji Othman bin Mustapha dalam majelis penutup Majelis Tilawah al-Quran 2015 menjelaskan terdapat kesalahan bacaan Qari dan Qariah berkaitan hukum Tajwid dan Fasohah seperti tertukar baris dan tertukar huruf. Selain itu juga, terdapat juga peserta yang tidak dapat membedakan sifat tebal nipis dan sifat isti'la dan istifal suatu huruf ( Muhammad Syafiee Salihin dll, kertas kerja seminar, 2016:467).

Selain itu, Muhammad Azhar Zailani memetik ucapan Zainal Abidin Ahmad, exco kerajaan negeri Selangor dalam akhbar
Utusan Malaysia bertarikh 10 Jan 1995 ( The Online Jurnal of Islamic Education, July 2015, Vol.3 Issue 2) menyatakan: “ Hampir 60\% pelajar Islam kini tidak boleh membaca al-Quran". Hal ini menunjukkan masalah lemah membaca al-Quran juga sering diperkatakan oleh guru-guru dan pengkajipengkaji dalam bidang pendidikan Islam. Muhammad Azhar mendapati bentukbentuk kesalahan yang berlaku adalah kesalahan-kesalahan dalam implementasi makhraj dan sifat huruf seperti kesalahan dalam implementasi dengung atau tidak dengung, implementasi tebal atau nipis dalam bacaan, kesalahan dalam bacaan panjang atau pendek, kesalahan dalam menunaikan baris atau huruf yang betul dan kesalahan dalam berhenti dan memulakan ayat

Berdasarkan kajian terdahulu, terdapat karya-karya dalam bentuk buku kurang memfokuskan kepada kesalahan-kesalahan dalam bacaan al-Quran. Selain itu, kajian mereka berkisarkan kepada penjelasan mengenai biodata qari atau qariah dan kemenangan mereka. Begitu juga, sorotan kajian lampau kurang memperinci aspekaspek kesalahan yang berlaku. Data yang terdapat masih dalam bentuk dokumentasi yang perlu dibuat kajian dan dianalisis untuk memberi manfaat kepada masyarakat. Namun begitu, terdapat kajian mutakhir yang mengkaji tentang kesalahan-kesalahan 
dalam bacaan tetapi memfokuskan kepada pelajar di IPT. Kajian yang berkaitan dengan Majelis Tilawah al-Quran (MTQ) pernah dijalankan pada tahun 2016, tetapi hanya menyentuh aspek tajwid dan fasahah sahaja dan tidak membincangkan aspek suara dan tarannum. Oleh itu, kajian yang akan dijalankan ini memfokuskan kepada empat aspek utama yaitu tajwid, Fasohah, suara dan tarannum dan lebih terkini karena melibatkan peserta qari dan qariah dalam MTQ pada tahun 2019.

\section{Bentuk-bentuk Kesalahan Bacaan al-}

\section{Quran Pelajar Di Sebuah IPTA}

Dalam sebuah artikel jurnal oleh Muhammad Azhar Zailani memuatkan bentuk-bentuk kesalahan bacaan al-Quran dalam kalangan pelajar di salah sebuah IPTA di Malaysia. Beliau mendapati antara bentuk-bentuk kesalahan yang paling tinggi dan sering dilakukan pelajar ialah :

\section{Bentuk-bentuk kesalahan pada sebutan Makhraj dan Sifat}

Kesalahan pada sebutan huruf-huruf Hijaiah, kesalahan sifat Hams atau jahr, kesalahan sifat Syiddah, tawassut dan rakhawah, kesalahan sifat itbaq, atau infitah, kesalahan sifat qalqalah, kesalahan sifat sofir, kesalahan sifat istitolah, kesalahan sifat inhiraf, kesalahan sifat Lin, kesalahan sifat ghunnah dan kesalahan sifat khafa'.

\section{Bentuk-bentuk kesalahan pada sebutan dengung dan tak dengung}

Antara bentuk kesalahan yang biasa dilakukan seperti tidak mengikhfa'kan nun pada Ikhfa' Haqiqi, tidak mendengungkan Nun bersabdu dengan dua harakat, tidak mendengungkan Ikhfa' haqiqi dengan dua harakat, tidak tetap dalam menunaikan hukum hakam dengung, tidak mendengungkan mim bersabdu dengan dua harakat, menipiskan dengung ketika nun bertemu huruf isti'la', mendengungkan yang tidak dengung, tidak mengikhfa'kan mim pada ikhfa' syafawi, tidak mendengungkan idhgam ma'al ghunnah dengan dua harakat, tidak mendengungkan ikhfa' syafawi dengan dua harakat, tidak menggabungkan suara pada idgham ma'al ghunnah, menebalkan dengung ketika Nun bertemu huruf Istifal, Tidak mengikhfa'kan mim pada Iqlab (Ikhfa' Majazi), tidak mendengungkan iqlab dengan dua harakat, mendengungkan lebih dari dua harakat, tidak menggabungkan suara pada Idgham bi la ghunnah. 
3. Bentuk-bentuk Kesalahan pada sebutan Tebal dan Tipis (tarqiq/ Tafkhim)

Seperti menebalkan huruf Istifal, menipiskan huruf isti'la', menebalkan sebutan ro' tipis, menipiskan sebutan ro' tebal dan menipiskan Lam jalalah tebal.

\section{Bentuk-bentuk kesalahan pada bacaan panjang dan pendek}

Antara bentuk kesalahan ialah memanjangkan dengan kadar yang lebih dari sepatutnya, memanjangkan huruf yang tidak sepatutnya panjang, Mad Lazim Kalimi Muthaqqal tidak dipanjangkan 6 harakat, tidak menyamakan kadar panjang antara mad-mad, mad munfasil tidak dipanjang 4 atau 5 harakat, Mad Muttasil tidak dipanjang 4 atau 5 harakat, memendekkan huruf yang sepatutnya panjang, Mad Lazim Harfi Mukhaffaf tidak dipanjangkan 6 harakat, Mad Asli tidak dipanjangkan 2 harakat, Mad Silah Kubra tidak dipanjangkan 4 atau 5 harakat, Mad asli Harfi tidak dipanjangkan 2 harakat, Mad Lazim Harfi Muthaqqal tidak dipanjangkan 6 harakat, dan Mad Badal tidak dipanjangkan 2 harakat.

\section{Bentuk-bentuk Kesalahan Huruf dan baris dalam Bacaan al-Quran}

Antara kesalahan ialah kesalahan fathah, kasrah, dhommah, sukun dan bersabdu, kesalahan mengurangkan huruf, kesalahan menambah huruf dan kesalahan menukar huruf.

\section{Bentuk-bentuk kesalahan dalam berhenti dan memulakan bacaan (Waqf/ Ibtida')}

Antara bentuk kesalahan ialah berhenti atau mengulang semula bacaan dengan menarik nafas, memulakan bacaan pada perkataan yang merusakkan struktur bahasa, berhenti pada perkataan yang merusakkan struktur tata bahasa, berhenti pada perkataan yang merusakkan maksud sebenar, berhenti dengan membariskan huruf akhir dan memulakan bacaan pada perkataan yang merusakkan maksud sebenar.

\section{Kaidah Penghakiman Majelis} Tilawah Al-Quran (MTQ) Peringkat Kebangsaan

Dalam buku Peraturan Majelis Tilawah al-Quran Peringkat Kebangsaan memuatkan kriteria pemarkahan bahagian penghakiman dalam tilawah al-Quran melibatkan empat perkara yaitu : 


\begin{tabular}{|l|l|l|}
\hline \multicolumn{1}{|c|}{ No. } & \multicolumn{1}{|c|}{ Bidang } & \multicolumn{1}{c|}{ Markah } \\
\hline 1 & Tajwid & 40 \\
\hline 2 & Tarannum & 25 \\
\hline 3 & Fasohah & 20 \\
\hline 4 & Suara & 15 \\
\hline
\end{tabular}

Sumber: Jakim, 2009

Perkara yang penting dalam dalam bacaan, tidak membaca ayat atau penghakiman bidang Fasohah ialah cermat dan fasih dalam bacaan, mahir menyebut kalimah-kalimah dan ayat-ayat, terpelihara segala huruf, harakat yaitu baris dan tashdid, menepati kaidah waqf dan ibtida' termasuk waqf jibril dan waqf nabawi, bacaan menurut lahjah arab fusha, bacaan sederhana tidak terlalu cepat atau terlalu lambat, dan tidak bercampur aduk antara bacaan tartil dan tadwir. Ciri-ciri bacaan istimewa dalam bidang Fasohah pula ialah bacaan dengan lahjah Arab, dapat menyempurnakan ayat yang panjang dalam satu nafas dan bacaan yang cermat dan bertadabbur.

Selain itu, antara perkara yang boleh merusakkan bacaan yang menjurus kepada pengurangan markah dalam bidang tajwid dan Fasohah ialah tersalah memulakan bacaan atau ayat yang ditetapkan, menamatkan bacaan melebihi 30 saat sebelum cukup tempoh yang diperuntukkan, surah yang telah ditetapkan dan jika berulang-ulang kesalahan nyata atau jaliy tiada kelancaran yang berterusan maka markah Fasohah dibatalkan atau tidak diberi markah.( Peraturan Majelis Tilawah alQuran Peringkat Kebangsaan, 2011).

Kaidah Pemotongan Markah Dalam

\section{Penghakiman}

Tesis peringkat Doktor Falsafah oleh Najmiah binti Omar berjudul "Pengajian Tarannum Al-Quran Di Terengganu Dari Tahun 1960-2013: Kajian Terhadap Metodologi Pengajaran Rogayah Binti Sulong” memuatkan kriteria pemotongan markah dalam bidang penghakiman dari aspek suara dan tarannum. Suara memainkan peranan yang penting dalam tilawah al-Quran. Antara kategori suara yang baik ialah seperti berikut:

\begin{tabular}{|l|l|l|l|}
\hline No. & Jenis suara & \multicolumn{1}{c|}{ Sifat suara } & \multicolumn{1}{c|}{ Tahap suara } \\
\hline 1 & Terbaik & $\begin{array}{l}\text { Ketepatan nada, tinggi, rendah, } \\
\text { garau, lembut, manis, licin, bersih, } \\
\text { terang, lantang dan tajam. }\end{array}$ & $\begin{array}{l}\text { Suara istimewa dan senang } \\
\text { dipelajari }\end{array}$ \\
\hline
\end{tabular}




\begin{tabular}{|l|l|l|l|}
\hline 2 & Baik & $\begin{array}{l}\text { ketepatan nada, sederhana, } \\
\text { rendah, garau, lembut, manis, } \\
\text { licin, bersih, terang, dan lantang. }\end{array}$ & $\begin{array}{l}\text { Suara istimewa dan senang } \\
\text { dipelajari }\end{array}$ \\
\hline 3 & Kurang baik & $\begin{array}{l}\text { Ketepatan nada, tinggi, kecil, } \\
\text { lembut, manis, licin, bersih, } \\
\text { terang dan tajam. }\end{array}$ & $\begin{array}{l}\text { Suara istimewa dan senang } \\
\text { dipelajari }\end{array}$ \\
\hline 4 & Tidak baik & $\begin{array}{l}\text { Sumbang, nipis, lembap, lemah, } \\
\text { keras, serak, pecah, parau, } \\
\text { terketar-ketar, tenggelam, tersepit, } \\
\text { terputus dan tercekik. }\end{array}$ & $\begin{array}{l}\text { adalah suara yang bermasalah } \\
\text { yang perlu diperbaiki dan } \\
\text { diubahsuai dalam jangka masa } \\
\text { yang panjang. }\end{array}$ \\
\hline
\end{tabular}

Sumber : Tesis PhD Najmiah binti Omar, 2017

Kaidah pemotongan suara dalam bidang penghakiman majelis tilawah al-Quran adalah seperti berikut.

Kaidah pemotongan markah dalam bidang suara

\begin{tabular}{|c|c|c|c|}
\hline Bidang & No. & Jenis suara & Pemotongan markah \\
\hline \multirow{12}{*}{ Suara } & 1 & Suara parau. & dipotong satu markah \\
\hline & 2 & Suara sumbang yang merusakkan & dipotong satu markah \\
\hline & 3 & Suara tenggelam & dipotong satu markah \\
\hline & 4 & Suara pecah dan terputus-putus & dipotong satu markah \\
\hline & 5 & Suara tersepit atau tercekik & dipotong satu markah \\
\hline & 6 & $\begin{array}{lrr}\text { Suara } & \text { terketar-ketar } & \text { karena } \\
\text { terlampau tinggi atau terlampau } \\
\text { rendah }\end{array}$ & dipotong satu markah \\
\hline & 7 & Suara yang tidak cukup tiga tabaqat & dipotong satu markah \\
\hline & 8 & Suara lemah dan kelembapan & dipotong satu markah \\
\hline & 9 & Suara yang keras dan kaku & dipotong satu markah \\
\hline & 10 & Suara yang berubah kualitas & dipotong satu markah \\
\hline & 11 & $\begin{array}{l}\text { Tidak membawa satu ikhtilal al- } \\
\text { Lahn bagi satu bacaan }\end{array}$ & dipotong satu markah \\
\hline & 12 & $\begin{array}{l}\text { Jika berulang-ulang pada kesalahan } \\
\text { yang sama }\end{array}$ & $\begin{array}{l}\text { dipotong markahnya dengan } \\
\text { kadar tidak melebihi lima } \\
\text { markah }\end{array}$ \\
\hline
\end{tabular}

Sumber : Tesis PhD Najmiah binti Omar, 2017 
Kaidah pemotongan markah dalam bidang tarannum

\begin{tabular}{|c|c|c|c|}
\hline Bidang & Bilangan & Kesalahan & Pemotongan markah \\
\hline \multirow{10}{*}{ Tarannum } & 1 & $\begin{array}{l}\text { Membaca kurang dari } \\
\text { empat jenis tarannum }\end{array}$ & $\begin{array}{l}\text { Setiap satu tarannum wajib } \\
\text { yang ditinggalkan dipotong } \\
\text { empat markah. }\end{array}$ \\
\hline & 2 & $\begin{array}{l}\text { Tidak membaca dua jenis } \\
\text { tarannum yang ditetapkan }\end{array}$ & $\begin{array}{l}\text { setiap satu daripada dua } \\
\text { tarannum yang ditinggalkan } \\
\text { dipotong empat markah. }\end{array}$ \\
\hline & 3 & $\begin{array}{l}\text { Membaca kurang daripada } \\
\text { empat harakat bagi setiap } \\
\text { tarannum }\end{array}$ & $\begin{array}{lrr}\text { Setiap } & \text { satu harakat } & \text { yang } \\
\text { kurang } & \text { dipotong } & \text { satu } \\
\text { markah. } & & \end{array}$ \\
\hline & 4 & $\begin{array}{l}\text { Tidak membawa tiga } \\
\text { tabaqat bagi setiap } \\
\text { tarannum }\end{array}$ & $\begin{array}{l}\text { Setiap satu tabaqat yang } \\
\text { tidak dibawa dipotong satu } \\
\text { markah. }\end{array}$ \\
\hline & 5 & Takrir pada tarannum & $\begin{array}{l}\text { Setiap satu kesalahan } \\
\text { dipotong satu markah. }\end{array}$ \\
\hline & 6 & Takrir pada harakat & $\begin{array}{l}\text { Setiap satu kesalahan } \\
\text { dipotong satu markah }\end{array}$ \\
\hline & 7 & $\begin{array}{l}\text { Meniru sepenuhnya ba- } \\
\text { caan mana-mana qari yang } \\
\text { masyhur }\end{array}$ & Dipotong satu markah. \\
\hline & 8 & $\begin{array}{l}\text { Tidak membawa satu } \\
\text { wuslah al-mumathalah dan } \\
\text { ikhtilal al-Lahn bagi satu } \\
\text { bacaan }\end{array}$ & Dipotong satu markah. \\
\hline & 9 & $\begin{array}{l}\text { Tarannum penutup tidak } \\
\text { sama dengan tarannum } \\
\text { pembukaan }\end{array}$ & Dipotong satu markah. \\
\hline & 10 & $\begin{array}{l}\text { Jika berulang-ulang kesal } \\
\text { dipotong markahnya deng } \\
\text { markah. }\end{array}$ & $\begin{array}{l}\text { han yang sama hendaklah } \\
\text { n kadar tidak melebihi lima }\end{array}$ \\
\hline
\end{tabular}

Sumber : Tesis PhD Najmiah binti Omar, 2017 
Kaidah pemotongan markah dalam bidang fasahah

\begin{tabular}{|c|c|c|c|}
\hline Bidang & Bilangan & Kesalahan & Pemotongan markah \\
\hline \multirow{6}{*}{ Fasahah } & 1 & $\begin{array}{l}\text { Tersalah memulakan bacaan } \\
\text { atau ayat ditetapkan }\end{array}$ & Dipotong satu markah \\
\hline & 2 & $\begin{array}{l}\text { Menamatkan bacaan melebihi } \\
30 \text { saat sebelum cukup tempoh } \\
\text { yang diperuntukkan }\end{array}$ & Dipotong satu markah \\
\hline & 3 & $\begin{array}{l}\text { Tertinggal atau melangkau ayat } \\
\text { semasa dalam bacaan }\end{array}$ & Dipotong dua markah \\
\hline & 4 & $\begin{array}{l}\text { Tidak membaca ayat atau surah } \\
\text { yang telah ditetapkan }\end{array}$ & $\begin{array}{l}\text { Bacaan ditolak atau tidak diberi } \\
\text { markah }\end{array}$ \\
\hline & 5 & $\begin{array}{l}\text { Jika berulang-ulang pada } \\
\text { kesalahan yang sama }\end{array}$ & $\begin{array}{l}\text { Hendaklah dipotong markahnya } \\
\text { dengan kadar tidak melebihi lima } \\
\text { markah. }\end{array}$ \\
\hline & 6 & $\begin{array}{l}\text { Jika berulang-ulang kesalahan } \\
\text { jaliy atau tiada kelancaran yang } \\
\text { berterusan }\end{array}$ & $\begin{array}{l}\text { Markah fasahah dibatalkan dan } \\
\text { tidak diberi markah. }\end{array}$ \\
\hline
\end{tabular}

Sumber : Tesis PhD Najmiah binti Omar, 2017

Kaidah pemotongan markah dalam bidang tarannum

\begin{tabular}{|c|c|c|c|}
\hline Bidang & Bilangan & Kesalahan & Pemotongan markah \\
\hline \multirow{4}{*}{ Tarannum } & 1 & $\begin{array}{l}\text { Membaca kurang dari empat } \\
\text { jenis tarannum. }\end{array}$ & $\begin{array}{l}\text { Setiap satu tarannum wajib yang } \\
\text { ditinggalkan dipotong empat } \\
\text { markah. }\end{array}$ \\
\hline & 2 & $\begin{array}{l}\text { Tidak membaca dua jenis } \\
\text { tarannum yang ditetapkan }\end{array}$ & $\begin{array}{l}\text { Setiap satu daripada dua } \\
\text { tarannum yang ditinggalkan } \\
\text { dipotong empat markah. }\end{array}$ \\
\hline & 3 & $\begin{array}{l}\text { Membaca kurang daripada } \\
\text { empat harakat bagi setiap } \\
\text { tarannum. }\end{array}$ & $\begin{array}{l}\text { Setiap satu harakat yang kurang } \\
\text { dipotong satu markah. }\end{array}$ \\
\hline & 4 & $\begin{array}{l}\text { Tidak membawa tiga tabaqat } \\
\text { bagi setiap tarannum. }\end{array}$ & $\begin{array}{l}\text { Setiap satu tabaqat yang tidak } \\
\text { dibawa dipotong satu markah. }\end{array}$ \\
\hline
\end{tabular}




\begin{tabular}{|l|l|l|l|}
\hline 5 & Takrir pada tarannum. & $\begin{array}{l}\text { Setiap satu kesalahan dipotong } \\
\text { satu markah. }\end{array}$ \\
\cline { 2 - 4 } & 6 & Takrir pada harakat. & $\begin{array}{l}\text { Setiap satu kesalahan sipotong } \\
\text { satu markah. }\end{array}$ \\
\cline { 2 - 5 } & 7 & $\begin{array}{l}\text { Meniru sepenuhnya bacaan } \\
\text { mana-mana qari yang masyhur }\end{array}$ & Dipotong satu markah \\
\hline 8 & $\begin{array}{l}\text { Tidak membawa satu wuslah al- } \\
\text { mumathalah dan ikhtilal al-Lahn } \\
\text { bagi satu bacaan. }\end{array}$ & Dipotong satu markah \\
\cline { 2 - 5 } & $\begin{array}{l}\text { Tarannum penutup tidak sama } \\
\text { dengan tarannum pembukaan }\end{array}$ & $\begin{array}{l}\text { Dipotong satu markah. } \\
\text { Jika berulang-ulang kesalahan } \\
\text { yang sama }\end{array}$ & $\begin{array}{l}\text { Dengan kadar tidak melebihi } \\
\text { lima markah. }\end{array}$ \\
\hline
\end{tabular}

Sumber : Tesis PhD Najmiah binti Omar, 2017

\section{KESIMPULAN}

Bacaan al-Quran yang bermutu adalah bacaan yang tidak mengandungi banyak kesilapan ketika mengalunkan ayat suci alQuran. Oleh itu, para qari dan qariah sewajarnya memelihara bacaan al-Quran agar tidak mempunyai banyak kesilapan karena ia mempengaruhi pemarkahan dan pemotongan markah. Dengan mempunyai pengetahuan tentang ciri-ciri kriteria yang disebutkan dalam artikel ini, sekurangkurangnya dapat dijadikan garis panduan dan bekalan untuk para qari dan qariah ketika hendak membaca al-Quran.

Kempat-empat aspek perlu dipelihara yaitu suara, tajwid, fasahah dan tarannum agar tidak banyak kesalahan dalam bacaan
al-Quran. Latihan yang berterusan dan konsisten serta berguru dengan guru yang terlatih dapat memantapkan mutu bacaan masing-masing.

\section{RUJUKAN}

Ahmad Syafik Mat Razali et al. Implikasi Ketokohan Qari-qari Tanah Melayu Terhadap Kewujudan Program Tarannum Di Malaysia: Satu Tinjauan. https://ejurnalfp.files.wordpress.com/2 015/02/implikasi -ketokohan-qari-qaritanah-melayu-terhadap-kewujudanprogram-tarannum-di-malaysia,pdf paparan pada 23 Jun 2016.

Fail Majelis Tilawah al-Quran, JHEAT 2015, Bahagian Pengurusan Masjid 
Tingkat 3, Majelis Agama Islam Dan adat Istiadat Negeri Terengganu, Kompleks Seri Iman, Kuala-Terengganu, Terengganu pada 12 Mei 2015.

Majelis Agama Islam Dan Adat Melayu Terengganu. Jabatan Hal Ehwal Dakwah, Pendidikan Dan Pengurusan Masjid, Pusat Pentadbiran Islam Negeri, Kompleks Seri Iman, Jalan Sultan Mohamad, 20676, Kuala Terengganu, Terengganu.
Mohamad bin Saari, Johan Qari dan Qariah Malaysia, Kuala Lum[pur: JAKIM, 2007.

Mohamad bin Saari, 50 Tahun Tilawah alQuran Malaysia, Putrajaya, JAKIM, 2008.

Mohd yusof Ahmad. Sejarah Dan Kaidah Pendidikan al-Quran. Cet. Ke-4. Kuala Lumpur: Universiti Malaya. 2005. 
Jurnal TAMADDUN - FAI UMG. Vol. XXI. No.1 / Januari 2020 